\title{
Tronco de Navidad
}

\author{
Bûche Noël
}

Tammara Ilce Guzmán López ${ }^{a}$, Víctor Issaí Naranjo Luna ${ }^{b}$

\begin{abstract}
:
Le Bûche Noël c'est un dessert traditionnel servi dans des divers pays européens, mais son origine se trouve en France. Le Bûche Noël se présente comme un dessert décoré en forme de tronc et qui est provient d'une tradition celte, pour fêter le solstice d'hiver pour localiser et récupérer un tronc d'arbre et le brûler dans le jour plus court de l'année. Cette tradition a été une manière de fêter aussi la renaissance du soleil et lui donner le remerciement pour la vie.
\end{abstract}

Keywords:

Bûche, dessert, celte, tronc

\section{Resumen:}

El tronco de navidad es un postre tradicional servido en diferentes países europeos, pero su origen se encuentra en Francia. El tronco de navidad se presenta como un postre decorado en forma de tronco y proviene de una tradición celta, para celebrar el solsticio de invierno para localizar y recuperar un tronco de árbol y quemarlo en el día más corto del año. Esta tradición fue una manera de festejar también, el renacimiento del sol y darle las gracias por la vida.

Palabras Clave:

Tronco de navidad, postre, celta

\section{Introducción}

El origen medieval del tronco de navidad es anterior al postre, ya que desde el siglo XII, era durante la navidad que existía un impuesto feudal llamado "derecho de registro", en el que los campesinos tenían que llevar un gran trozo de madera a la casa del señor feudal.

Posteriormente los campesinos hicieron esta tradición suya consistiendo en encontrar un pedazo de tronco para navidad, decorándolo con cintas verdes, sal y vino y quemándolo en la chimenea por el más pequeño de la familia, mientras cantaban especies de villancicos. Las cenizas de este tronco eran guardadas en una bolsa durante todo el año para proteger a la familia de desastres.

\section{Su origen en Francia}

Debido a las constantes enfermedades que sufría el pueblo francés a consecuencia de las chimeneas de las casas, Napoleón I ordenó cerrarlas durante los meses de invierno para que no entrara el frío y por esta razón, la tradición de quemar el tronco se perdió.

Fue así como, hasta 1898, Pierre de Lacam, un pastelero francés creó el Bûche Noël o tronco de navidad, un postre relleno de crema pastelera de chocolate o crema de mantequilla de café que se asimilaba al troco que se debía quemar en las fechas de invierno.

\section{La receta actual}

Fue hasta 1905 que Josep Fabre creó la receta ilustre que más se asemeja a la receta actual y que fue publicada en su libro "Dictionnaire universel de cuisine pratique". Este postre consta de una receta de bizcocho genovés, rectangular y plano, que se enrolla y se rellena de nata, chocolate o crema pastelera y por último se adorna.

\footnotetext{
a Profesor de asignatura Área Académica de Gastronomía, Universidad Autónoma del Estado de Hidalgo, Instituto de Ciencias Económico Administrativas, Email: tammara_guzman9945@uaeh.edu.mx

${ }^{\mathrm{b}}$ Profesor de asignatura Área Académica de Gastronomía Universidad Autónoma del Estado de Hidalgo, Instituto de Económico Administrativas, Email: victor_naranjo10022@uaeh.edu.mx
} 


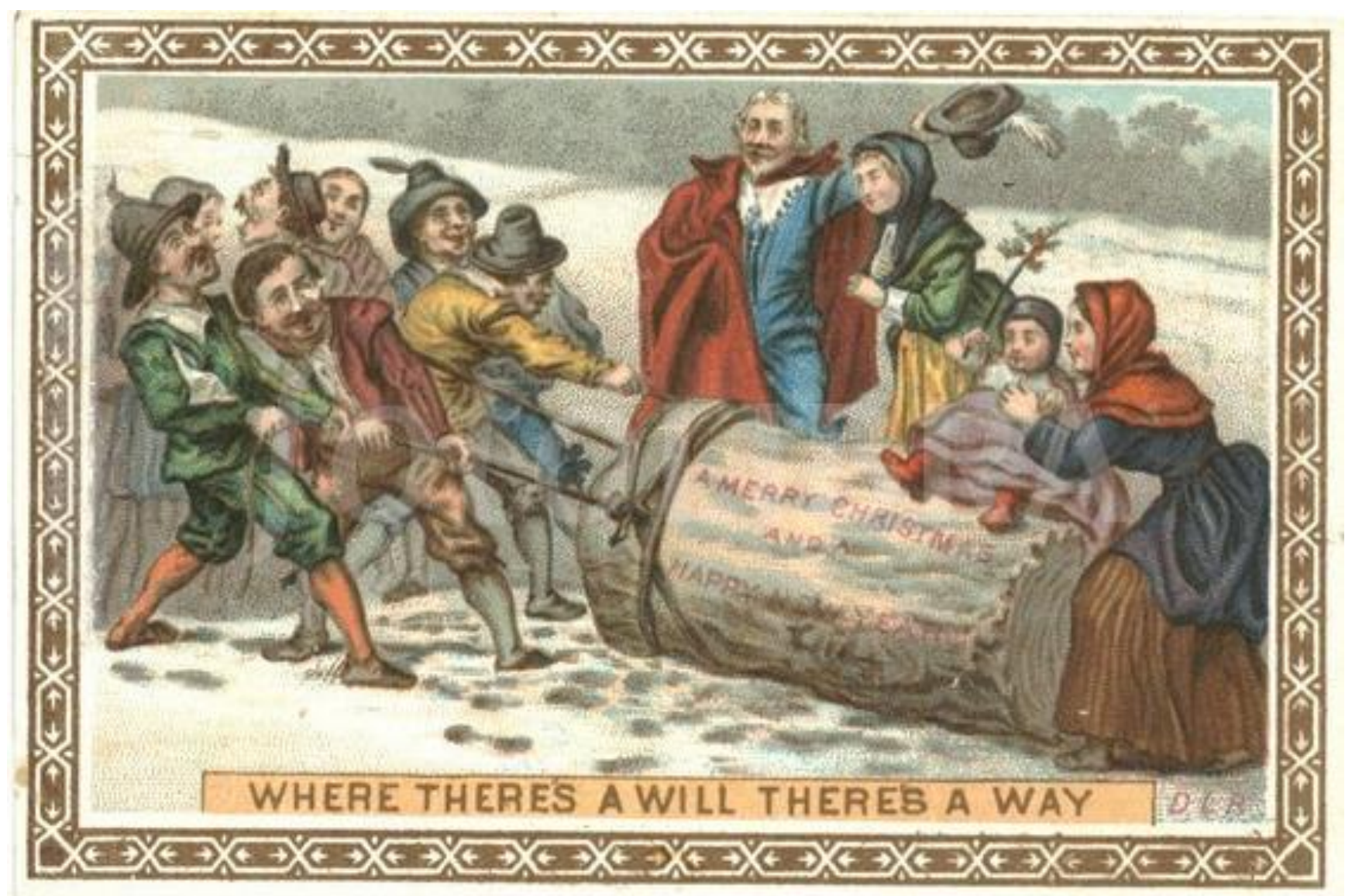

Figura 1. Tradición Celta. Tronco que se quemaba en Navidad.

Fuente: https://postresoriginales.com/francia-tronco-de-navidad/

\section{Referencias}

[1] Postres originales. Francia- Tronco de Navidad. Postres Originales 2014; https://postresoriginales.com/francia-tronco-de-navidad/

[2] Pierre Hermé. Le Larousse des desserts. Larousse 2006; ISBN 978-2-03-584136-0 